www.jmscr.igmpublication.org

Impact Factor 5.84

Index Copernicus Value: 83.27

ISSN (e)-2347-176x ISSN (p) 2455-0450

crossref DOI: _https://dx.doi.org/10.18535/jmscr/v5i7.49

Journal Of Medical Science And Clinical Research

\title{
A Case Report of a Rare Peripheral Odontogenic Fibroma
}

\author{
Authors \\ Dr Monika Goswamy ${ }^{1}$, Dr Saurabh Gupta ${ }^{2}$, Dr Harikesh Rao ${ }^{3}$, Dr Geetha K Bhat ${ }^{4}$ \\ Dr Syeda Tawkhira Tabasum ${ }^{5}$, Dr Praveen Kudva ${ }^{6}$, Dr. Vela Desai ${ }^{7}$ \\ ${ }^{1}$ Professor, Department of Periodontology and Implantology \\ ${ }^{2}$ Senior Lecturer, Department of Periodontology and Implantology \\ ${ }^{3}$ Professor, Department of Prosthodontics and Implantology \\ ${ }^{4}$ Reader, Department of Periodontology and Implantology \\ ${ }^{5}$ Professor, Department of Periodontology and Implantology \\ ${ }^{6}$ Professor and HOD Department of Periodontology and Implantology \\ ${ }^{7}$ Professor and HOD, Department of Oral Medicine and Radiology \\ Jaipur Dental College, NH 11-C, Kukas, Dhand, Jaipur 302028 \\ Corresponding Author \\ Dr Monika Goswamy
}

Professor, Jaipur Dental College, B-206 Trimurty apartments, Opp. Telecom colony,

Model town, Malviya Nagar, Jaipur-302017 Rajasthan

Mobile No.9929796568, Email: raomonikag@yahoo.co.in

\begin{abstract}
There are a variety of different types of focal proliferative lesions which may occur on the gingiva, some neoplastic but others inflammatory. At one time the terms "peripheral ossifying fibroma" and "peripheral odontogenic fibroma" were used interchangeably. The World Health Organization (WHO) however, in its classification of odontogenic tumours has used the term "peripheral odontogenic fibroma" for a specific entity quite separate from "peripheral ossifying fibroma". The peripheral odontogenic fibroma in distinct contrast to peripheral ossifying fibroma, is a rare lesion. This article reports a rare case of peripheral odontogenic fibroma in the maxilla.
\end{abstract}

Keywords: maxilla, peripheral, odontogenic, fibroma.

\section{INTRODUCTION}

Peripheral odontogenic fibroma (POdF) is an uncommon dental lesion regarded by WHO as a benign odontogenic neoplasm derived from fibroblast. ${ }^{[1]}$

Gardner ${ }^{[2]}$ was the first to define POdF, which was initially thought to be a rare extraosseous counterpart to central odontogenic fibroma and distinct from peripheral ossifying fibroma ${ }^{\text {[3]. }}$

The World Health Organization defined it as a benign odontogenic neoplasm of fibroblastic origin characterized by relatively mature collagenous fibrous tissue and varying amounts of odontogenic epithelium with potential to occur in 
either a central or an extraosseous location. The extraosseous counterpart is designated as peripheral odontogenic fibroma. ${ }^{[4]}$

POdF was designated specially in the past also as 'odontogenic gingival epithelial hamartoma' by Baden ${ }^{[5]} \&$ his co- workers and as 'peripheral ameloblastic fibrodentinoma' by numerous oral pathologists such as McKelvy and Cherrick. ${ }^{[6]}$

POdF is an uncommon lesion of the gingiva and more prevalent in females in the second decade of life $\mathrm{e}^{[2,7]}$ and there is a trend towards occurrence in the posterior mandible. ${ }^{[8]}$ It appears as a slow growingmass, often present for a number of years.It is generally described as a solid, firmly attached gingival mass, sometimes arising between teeth and sometimes even displacing the teeth.

The purpose of this article is to describe a rare case of POdF presenting as a fibrous swelling on the palate.

\section{CASE REPORT}

A 30 year, male presented to the Department of Periodontics, Jaipur Dental College, with a chief complaint of a localized swelling in the interdental gingiva between the upper left first and second premolars and extending to the palate. The gingival growth was present since six months and had been slowly increasing in size, causing displacement of both the teeth creating a space between the upper left premolars. There wasno history of a similar kind of swelling in the past.

Extraoral examination revealed no significant findings. Intraoral examination revealed a unilateral gingival overgrowth extending to the palate of the left side (Figure 1).

On examination, the swelling was approximately $0.8 \mathrm{X} 1 \mathrm{~cm}$ in size. It was pedunculated, nonlobulated, but of the same color as the surrounding mucosa. The probing depth in between the $1^{\text {st }}$ and $2^{\text {nd }}$ premolar was $8 \mathrm{~mm}$.Patient had a fair oral hygiene.

On palpation the swelling was oval in shape with defined borders. It was fibrotic in consistency, non-motile and non-tender.
A provisional diagnosisof Localized Chronic Periodontitis with focal fibrous hyperplasia/ irritation fibroma was made. The intraoral periapical radiograph of the involved area revealed horizontal bone loss. Excisional biopsy of the entire overgrowth was done and the specimen was sent for histopathological examination (Figure 2).

Microscopically, the lesion showed partially circumscribed tumor mass exhibiting interlacing fascicles of collagen fibers, islands of odontogenic epithelial cells and scattered abundant odontogenic nests and strands. Intervening connective tissue also consisted of numerous localized areas of chronic inflammatory cells (mainly plasma cells), blood vessels, lymphocytes \&fibroblasts. The overlying epithelium was hyperplastic;parakeratinized stratified squamous epithelium with thin, long rete ridges (Figures 5, $6)$.

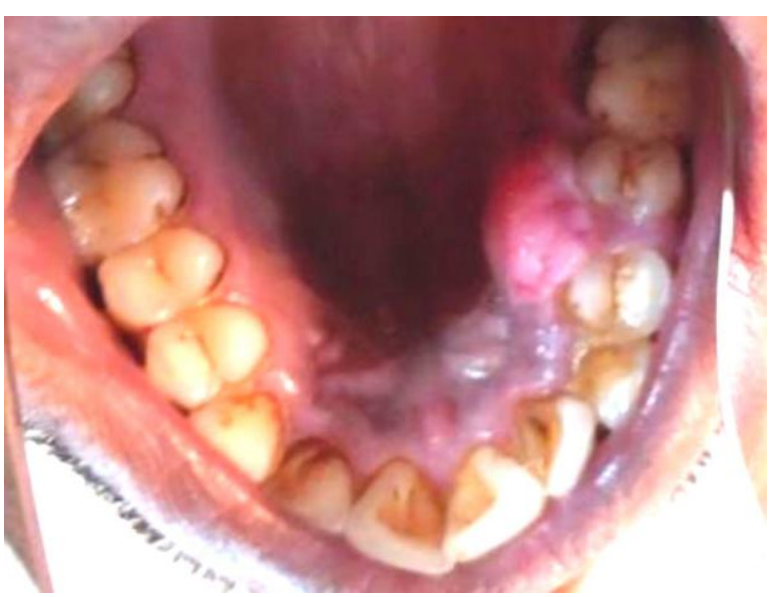

Fig 1: Intraoral view showing a unilateral gingival overgrowth extending to the palate

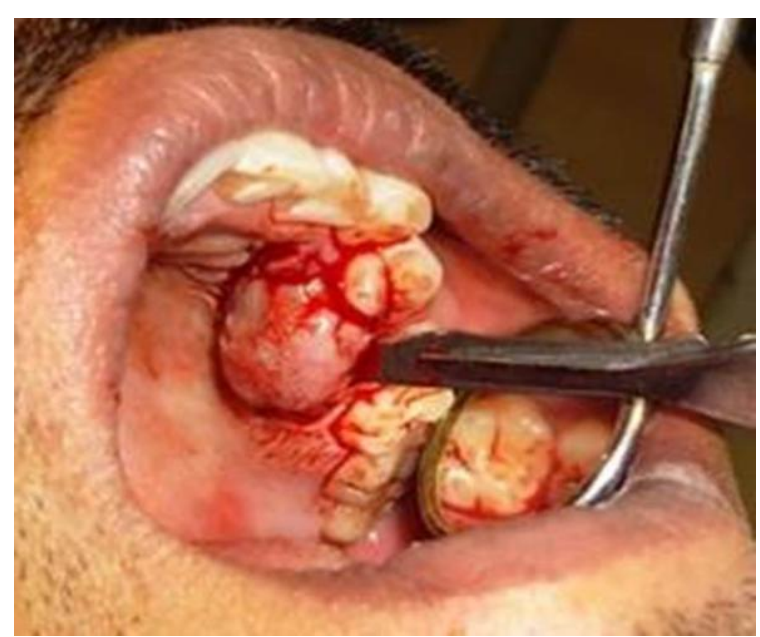

Fig 2: Excisional Biopsy of the overgrowth 


\section{JMSCR Vol||05||Issue||07||Page 24588-24591||July}

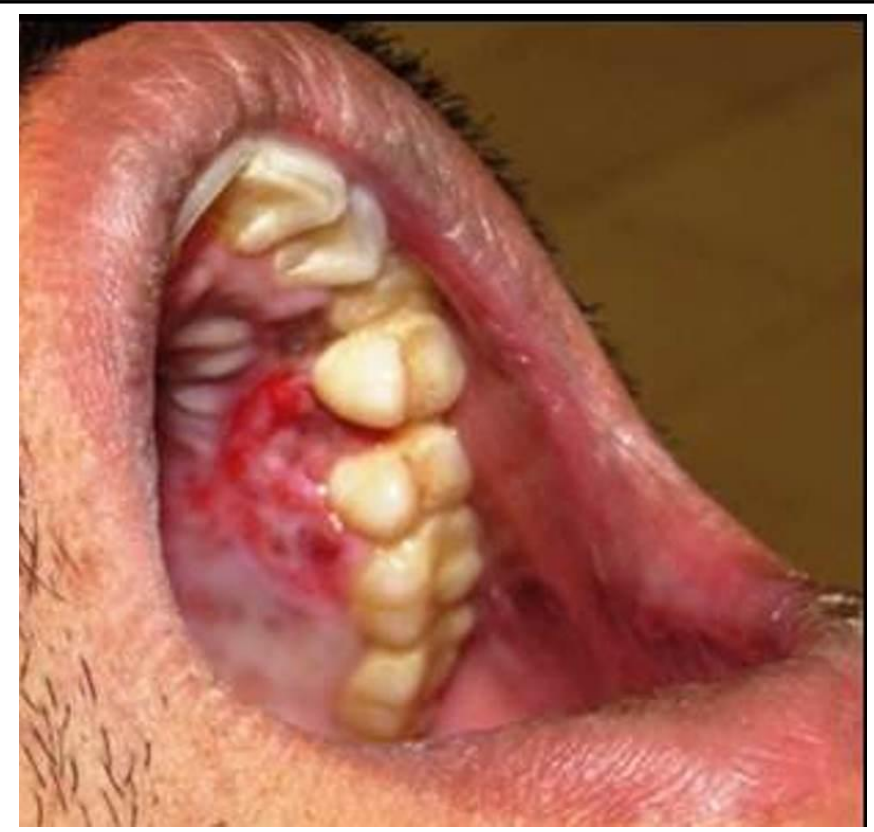

Fig 3: One week postoperative

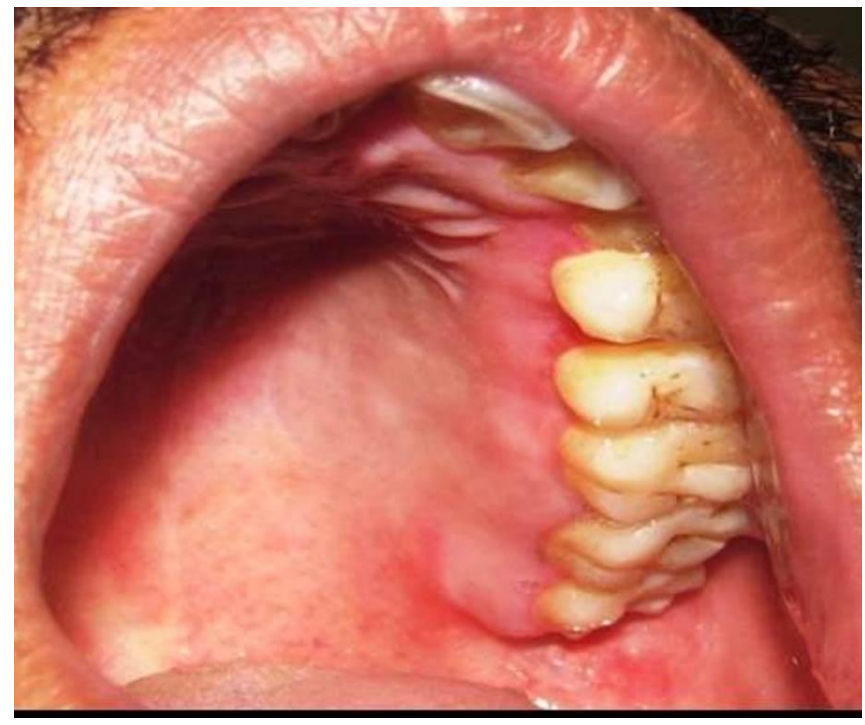

Fig 4: Postoperative after 2 years

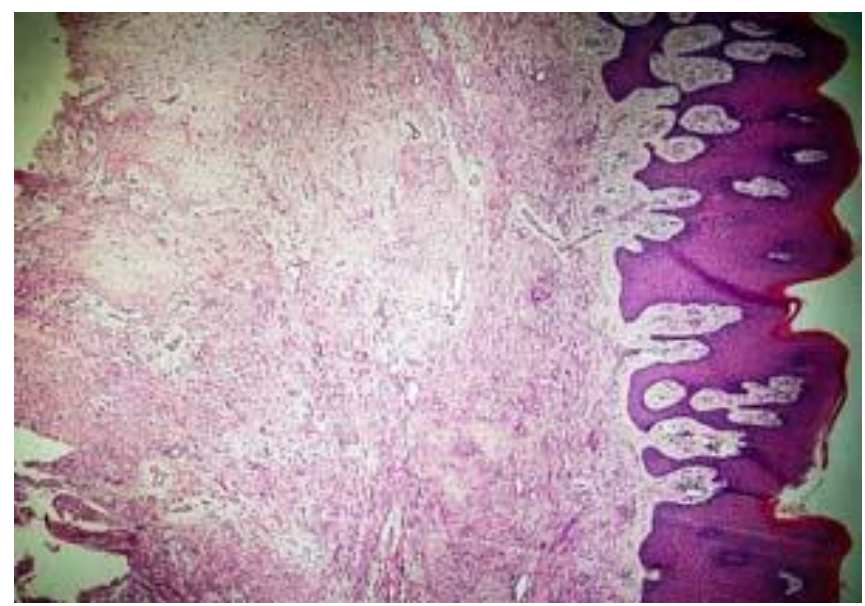

Fig 5: Microphotograph showing hyperplastic, parakeratinized, stratified squamous epithelium with thin long rete pegs

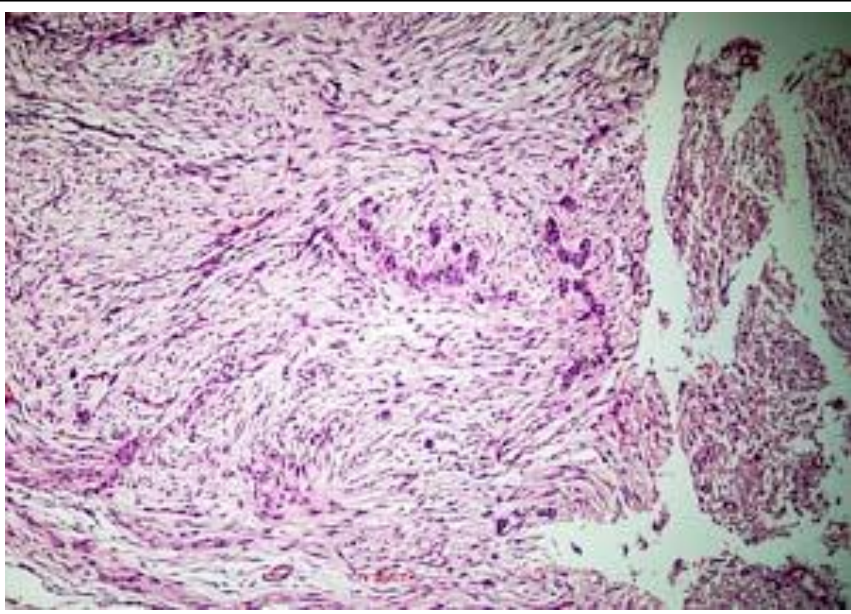

Fig 6: Microphotograph showing presence of islands of odontogenic epithelial cells

\section{DISCUSSION}

Peripheral odontogenic fibroma is a rare benign mesenchymal odontogenic neoplasm with or without odontogenic epithelium, which typically presents as a raised firm,painless, smoothsurfaced gingival mass. ${ }^{[9]}$

It is considered to be the mucosal analog to the central odontogenic fibroma. ${ }^{[10]}$

Though peripheral odontogenic tumours are rare, comprising only $0.05 \%$ of all biopsy specimens, POdF is the most common peripheral odontogenic tumour, even more common than its central counterpart by a ratio of $1: 4: 1 .^{[11]}$

The differential diagnosis includes inflammatory lesion such as fibrous hyperplasia, giant cell fibroma, peripheral ossifying fibroma, peripheral giant cell granuloma and pyogenic granuloma. ${ }^{[12]}$

The gingival overgrowth in this case report appeared similar to peripheral ossifying fibroma clinically. However presence of islands of odontogenic epithelium in the histological findings was suggestive of a peripheral odontogenic tumour.

A diagnosis of pyogenic granuloma was ruled out as histopathologically there was no presence of granulation tissue and vast number of endothelial lined vascular spaces. The peripheral giant cell granuloma hasfoci of haemorrhage with liberation of hemosiderin pigments and its ingestion by mononuclear phagocytes which are not seen in POdF. ${ }^{[9]}$ 
Graciaand colleagues (2007) observed a much higher prevalence of these lesions in females $(88.2 \%) .{ }^{[13]}$ The site of frequent occurrence was found to be the mandible $(69.3 \%) .^{[11]}$

In the 15 reported cases so far, site of occurrence in 11 cases was mandible and only4 in themaxilla. Unlike this, in this case report the growth was present in the maxilla and patient was a male.

The treatment is to ensure complete surgical excision of the lesion which may sometimes result in a mucogingival defect. In that case a combination of excisional biopsy and periodontal plastic surgery is a one-step procedure.

Prognosis is excellent and the recurrence rate of POdF has been reported to be from very low to as high as $38.9 \%$.

This case highlights the presence of peripheral odontogenic fibroma in the maxillary region of a male patient which is a rare case. There was no recurrence seen till two years of follow up (Figure 4). Diagnosis was based on clinical, histopathological as well as radiographic findings.

\section{ACKNOWLEDGEMENTS}

Dr. Shalabh Srivastava, Reader, Department of Oral Pathology for his valuable help in diagnosis of the overgrowth in this case.

\section{Conflicts of interest: Nil}

\section{REFERENCES}

1. Philipson HP, Reichart PA, Sciubba JJ, et al. Odontogenic tumours. In: Barnes L, Eveson JW, Reichart P, et al, eds. World Health organization classification of tumours. Pathology and Genetics of Head and Neck Tumours. Lyon: IARC Press, 2005: 283-327.

2. Gardner DG. The central odontogenic fibroma: an attempt at clarification. Oral Surg Oral Med Oral Pathol 1980; 50: 42532.
3. Gardner DG. The peripheral odontogenic fibroma: an attempt at clarification. Oral Surg Oral Med Oral Pathol 1982; 54: 40-8.

4. Weber A, van Heerden WFP, Lighthelm AJ, Raubenheimer EJ. Diffuse peripheral odontogenic fibroma: report of 3 cases. J Oral Pathol Med.1992; 21:82-4.

5. Baden E, Moskow BS, Moskow R. Odontogenic gingival epithelial hamartoma. J Oral Surg.1968; 26:702-14.

6. Mckelvy BD, Cherrick HM. Peripheral ameloblastic fibrodentinoma. $\mathrm{J}$ Oral surg. 1976; 34:826-9.

7. Slabbert HDV, Altini M. Peripheral odontogenic fibroma: a clinicopathologic study. Oral Surg oral Med oral Pathol 1991; 72:86-90.

8. Kenney JN, Kaugars GE, Abbey LM. Comparison between the peripheral ossifying fibroma and peripheral odontogenic fibroma. J Oral Maxillofacial Surg 1989; 47:378-82.

9. Shafers, Hine. Textbook of Oral Pathology 5thedition,pg. 292- 293.

10. Michaelides PL. Recurrent peripheral odontogenic fibroma of the attached gingiva: A case report. J Periodontol 1992; 63:645-7.

11. Buchner A, Merrell PW, Carpenter WM, Relative frequency of peripheral odontogenic tumours: A study of 45 new cases and comparison with studies from literature. J Oral PatholMed 2006;35:385-91

12. Manor Y, Merdinger O, Katz J, Taicher S. Unusual peripheral odontogenic tumours in the differential diagnosis of gingivalswellings. J Clin Periodontal 1999;26:806-9.

13. Gracia BG, Johann ACBR, Silvera-Junior JBDA, et al. Retrospective analysis of Peripheral odontogenic fibroma (WHOtype) in Brazilians. Minerva Stomatologica 2007; 56:115-9. 